\title{
Final Report: Stability and Novel Properties of Magnetic Materials and Ferromagnet / Insulator Interfaces
}

Project DE-FG02-99ER45777, Y. Austin Chang, PI and Paul M. Voyles, co-PI

Prof. Chang was supported by various incarnations of the Department of Energy, Basic Energy Sciences, Electron and Scanned Probe Microscopy program from 1999. The direction and nature of his research have evolved substantially over that time. From 1999 to 2002, his group studied diffusion of intermetallics for structural applications at high temperatures such as the prototype triple-defect B2 NiAl, then later tetragonal $\mathrm{L1}_{0}$ intermetallics. From 2002 to 2005, the project evolved to study antiferromagnetic (AFM) L1 $1_{0}$ materials such as NiMn and PtMn. Sputtered films of these intermetallics have a metastable fcc structure and are not ferromagnetic. He studied the phase transformation of the paramagnetic to antiferromagnetic phase transformation of Pt-Mn and Ni-Mn thin films. That research was Chang's introduction to magnetic materials and the materials problems associated with magnetic data storage, since AFM materials play a key role in giant magnetoresistance (GMR) and magnetic tunnel junction (MTJ) sensors used in magnetic hard disk drives.

From 2005 to 2008, Chang's research shifted to the spin dependent tunneling and interface stability problems inherent to magnetic tunnel junction (MTJ) structures. An MTJ consists of two ferromagnetic (FM) electrodes, one of which has its magnetization pinned to an adjacent AFM layer by exchange bias, separated by an insulating tunnel barrier layer such as $\mathrm{AlO}_{\mathrm{x}}$. $\mathrm{PtMn} / \mathrm{CoFe} / \mathrm{AlO}_{\mathrm{x}} / \mathrm{CoFe}$ is a prototype structure, but the synthesis of structures in which fundamental material and interface properties can be meaningfully measured is extremely challenging, since it requires controlling a variety of extrinsic characteristics such as surface and interface roughness and interdiffusion. Chang's group was the first to experimentally isolate and demonstrate the theoretically predicted effect on the junction of the crystal structure of the FM electrode. They isolated the effect of crystal structure from the effect of composition by using strain energy from lattice mismatch with different buffer layers to induce a $\mathrm{Co}_{87} \mathrm{Fe}_{13}$ electrode to be either fcc or bcc. They found a significant increase in the TMR for a bcc- $\mathrm{Co}_{87} \mathrm{Fe}_{13}$ electrode compared to a fcc- $\mathrm{Co}_{87} \mathrm{Fe}_{13}$ electrode, which indicates higher $s$-electron spin polarization for the bcc structure. The higher polarization was confirmed for bulk $\mathrm{Co}$ and $\mathrm{Co}_{87.5} \mathrm{Fe}_{12.5}$ by ab initio calculations. These results also showed experimentally that the strain of the FM electrode could change the TMR of a MTJ. By carefully controlling the FM crystal structure, post-annealing effects, and interface roughness and strain states, Chang and his group developed novel approaches to synthesize these structures and obtained the highest TMR at room temperature for $\mathrm{AlO}_{\mathrm{x}}$-based junctions reported in the literature.

Co-PI Paul Voyles joined the project in 2008 and assumed management of the project on Prof. Chang's death in 2011. Prof. Chang was an outstanding mentor, colleague, and friend. This report focuses on the accomplishments of the final two years of the project, which are dedicated to his memory.

\section{High-quality $\mathrm{Fe}_{3} \mathrm{O}_{4}$ thin films on TiN buffered Si substrates}

$\mathrm{Fe}_{3} \mathrm{O}_{4}$ with $-100 \%$ spin polarization (SP) at room temperature (RT) and high Curie temperature of $\sim 850 \mathrm{~K}$ is a quite promising magnetic material for spintronic devices. Fabricating smooth, low defect density and single phase $\mathrm{Fe}_{3} \mathrm{O}_{4}$ is essential for achieving high performance in devices like MTJs. We first fabiricated $\mathrm{Fe}_{3} \mathrm{O}_{4}$ thin film on TiN buffered Si (001) substrate by reactive sputtering, ${ }^{1}$ however, as shown in Figure 1 (a), grain boundaries in the film cause large surface 
roughness, as indicated by an orange arrow, which suggests that $\mathrm{Fe}_{3} \mathrm{O}_{4}$ grown by reactive sputtering is not suitable for spintronic devices. Figure 1 (b) shows the magnetization loops for the $\mathrm{Fe}_{3} \mathrm{O}_{4}$ thin films grown at different substrate temperature. They show that high temperature growth improves the saturation magnetization of the $\mathrm{Fe}_{3} \mathrm{O}_{4}$ thin films. However, even the magnetization loop of $\mathrm{Fe}_{3} \mathrm{O}_{4}$ grown at $400{ }^{\circ} \mathrm{C}$ shows a hard saturation magnetization even at high applied magnetic field, which suggests that the $\mathrm{Fe}_{3} \mathrm{O}_{4}$ thin films grown by reactive sputtering have a high density of antiferromagnetically coupled anti-phase boundaries (APBs). ${ }^{2}$

In order to fabricate $\mathrm{Fe}_{3} \mathrm{O}_{4}$ thin film with smoother surface and less APBs, we selectively oxidize $\mathrm{Fe}$ thin films using a $\mathrm{CO}_{2} / \mathrm{CO}$ gas mixture, which allows $\mathrm{Fe}_{3} \mathrm{O}_{4}$ to form in thermodynamic equilibrium. ${ }^{1,3} \mathrm{We}$
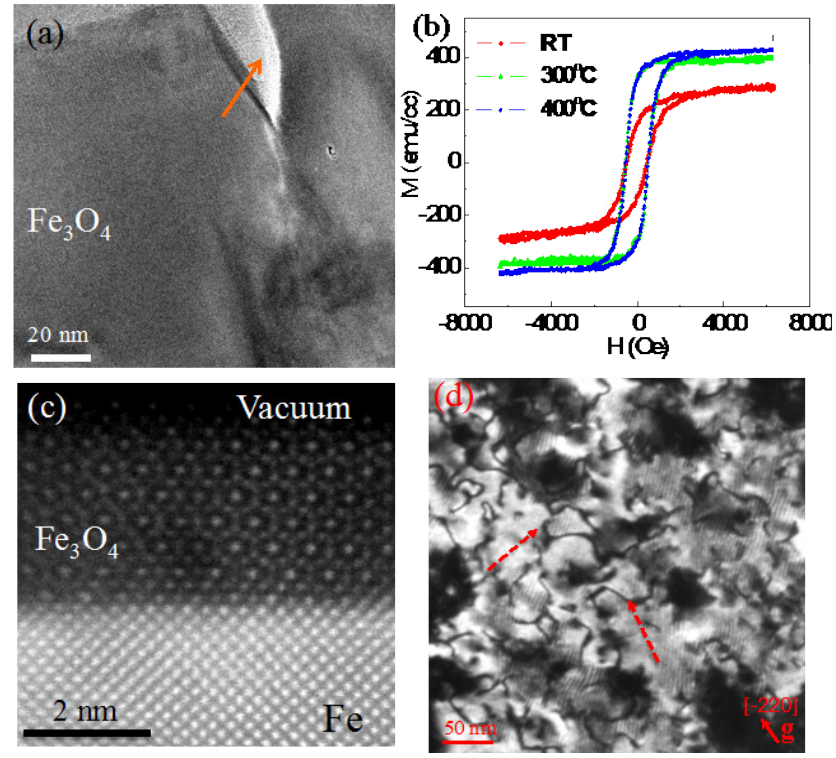

Figure 1 TEM image on $\mathrm{Fe}_{3} \mathrm{O}_{4}$ thin film grown by reactive sputtering. (b) The magnetization loop of the $\mathrm{Fe}_{3} \mathrm{O}_{4}$ thin films grown by sputtering at RT, $300{ }^{\circ} \mathrm{C}$ and $400{ }^{\circ} \mathrm{C}$ substrate temperature. (c) HRSTEM image of $\mathrm{Fe}_{3} \mathrm{O}_{4} / \mathrm{Fe}$ bilayer synthesized by selective oxidation. (d) Dark field TEM image using the 220 reflection for the [001] orientated $\mathrm{Fe}_{3} \mathrm{O}_{4}$ thin film oxidzed at $160{ }^{\circ} \mathrm{C}$ with a thickness of $19.34 \mathrm{~nm}$.

have obtained a much smoother $\mathrm{Fe}_{3} \mathrm{O}_{4}$ thin film with rms roughness $0.34 \pm 0.03 \mathrm{~nm}$ shown in Figure 1 (b), suitabl for spintroncs. ${ }^{4}$ We observed a second phase formed at the interface of $\mathrm{Fe}$ and TiN after oxidation at $400{ }^{\circ} \mathrm{C}$, but it can be avoided using lower growth oxidatin such as $160{ }^{\circ} \mathrm{C}$. The APB structure of a $\mathrm{Fe}_{3} \mathrm{O}_{4}$ thin film grown at $160{ }^{\circ} \mathrm{C}$ with a thickness $19 \mathrm{~nm}$ is shown in Figure . The antiphase domain size of the $\mathrm{Fe}_{3} \mathrm{O}_{4}$ thin film grown at $160{ }^{\circ} \mathrm{C}$ is $50 \sim 100 \mathrm{~nm}$, which is more than twice the length and four times the area of previous antiphase domains in $\mathrm{Fe}_{3} \mathrm{O}_{4}$ thin films with similar thickness grown on $\mathrm{Al}_{2} \mathrm{O}_{3}$ substrate. ${ }^{5}$ The size of anitiphase domains in $\mathrm{Fe}_{3} \mathrm{O}_{4}$ generally increases with film thickness, but the domain size for our $\mathrm{Fe}_{3} \mathrm{O}_{4}$ thin film is comparable to or even larger than previously reported for $50 \mathrm{~nm}$ thick $\mathrm{Fe}_{3} \mathrm{O}_{4}$ thin films on $\alpha-\mathrm{Al}_{2} \mathrm{O}_{3}(0001)$ by $\mathrm{MBE}^{5}$ and $\mathrm{MgO}$ substrates. ${ }^{6}$ The magnetization loop of this structure (not shown) is dominated by residual $\mathrm{Fe}$ below the $\mathrm{Fe}_{3} \mathrm{O}_{4}$. We also found at $160{ }^{\circ} \mathrm{C}$, the $\mathrm{Fe}_{3} \mathrm{O}_{4}$ thickness follows a $1 \frac{1}{4}$ power law in time.

In conclusion, compared to reactive sputtering, selective oxidation can yield a $\mathrm{Fe}_{3} \mathrm{O}_{4}$ thin film with low-defect density, smoother surface, which makes this method suitable for nanoscale spintronic applications on $\mathrm{Si}$.

\section{High-quality $\mathrm{Fe}_{4} \mathrm{~N}$ and $\left(\mathrm{Co}_{x} \mathrm{Fe}_{1-x}\right)_{4} \mathrm{~N}$ thin films on TiN buffered Si substrate}

$\mathrm{Fe}_{4} \mathrm{~N}$ is a promising material for spintronic devices with nearly $-100 \%$ SP at Fermi level at RT. ${ }^{7}$ We fabricated $\mathrm{Fe}_{4} \mathrm{~N}$ thin films by reactive sputtering ${ }^{8}$ and explored several growth parameters including substrate temperatures and $\mathrm{N}_{2}$ concentrations. Annealing the $\mathrm{Fe}_{4} \mathrm{~N}$ thin film under $30 \%$ $\mathrm{N}_{2}$ gas environment can prevent the $\mathrm{Fe}_{4} \mathrm{~N}$ from decomposing as it will in air or vacuum at that temperature. Epitaxial $\mathrm{Fe}_{4} \mathrm{~N}$ thin films prepared at $300{ }^{\circ} \mathrm{C}$ and $30 \% \mathrm{~N}_{2}$ are shown in the Figure 2(a), which shows a good epitaxial relationship. In Figure 2 (b) EELS data shows that the N/Fe 
atomic ratio is $0.2 \pm 0.027$, which means the resulting $\mathrm{Fe}_{4} \mathrm{~N}$ film is nearly stoichiometric. Magnetic property were also investigated. We found that after post annealing the sample, the magnetization easy axis followed the Fe easy axis [110] which is also consistent with the XRD data.

$\mathrm{Fe}_{4} \mathrm{~N}$ is metastable and easily decomposes by $\mathrm{N}$ desorption during interfacial oxidation and $\mathrm{Fe}_{3} \mathrm{O}_{4}$ formation as shown in Figure 2 (c). In Figure 2 (c), there is oxide layer on top of $\mathrm{Fe}_{4} \mathrm{~N}$ thin film after leaving the uncapped $\mathrm{Fe}_{4} \mathrm{~N}$ thin film in air. EEL spectrum of the oxidation layer is consistent with our measurement on a $\mathrm{Fe}_{3} \mathrm{O}_{4}$ standard. The phase transformation from $\mathrm{Fe}_{4} \mathrm{~N}$ to $\mathrm{Fe}_{3} \mathrm{O}_{4}$ at $\mathrm{RT}$ is thermodynamically favorable, since the standard Gibbs formation energy of $\mathrm{Fe}_{4} \mathrm{~N}$ and $\mathrm{Fe}_{3} \mathrm{O}_{4}$ are $+3.8 \mathrm{~kJ} / \mathrm{mol}$ and $-1015.4 \mathrm{~kJ} / \mathrm{mol}$, respectively. At the $\mathrm{Fe}_{4} \mathrm{~N} / \mathrm{Fe}_{3} \mathrm{O}_{4}$ interface, an intermediate layer also shows up in Figure 2(c). The intermediate layer has a bigger lattice constant than the $\mathrm{Fe}_{4} \mathrm{~N}$ thin film. EELS result in Figure 2 (d) also shows $\mathrm{N} \mathrm{K}, \mathrm{O} \mathrm{K}$ and $\mathrm{Fe} \mathrm{L}$ edges on the intermediate layer. EELS quantification shows that the composition of the intermediate layer is close to $\varepsilon$ $\mathrm{Fe}_{2} \mathrm{~N}$, which is consistent with previous work. ${ }^{9,10,11}$ In addition, both $\mathrm{Fe}_{3} \mathrm{O}_{4}$ and $\mathrm{Fe}_{4} \mathrm{~N}$ have the cubic crystal structure. Since the lattice parameter of $\mathrm{Fe}_{4} \mathrm{~N}(0.3795 \mathrm{~nm})$ is about half of that of $\mathrm{Fe}_{3} \mathrm{O}_{4}(0.8396 \mathrm{~nm})$, eight $\mathrm{Fe}_{4} \mathrm{~N}$ unit cells can convert into one $\mathrm{Fe}_{3} \mathrm{O}_{4}$ unit cell with $\sim 10 \%$ lattice mismatch, which makes the formation of $\mathrm{Fe}_{3} \mathrm{O}_{4}$ on $\mathrm{Fe}_{4} \mathrm{~N}$ lattice favorable.

$\mathrm{Co}_{4} \mathrm{~N}$ is also a ferromagnetic material with the same fcc structure as $\mathrm{Fe}_{4} \mathrm{~N} .^{12,13}$ Similar to $\mathrm{Fe}_{4} \mathrm{~N}$, $\mathrm{Co}_{4} \mathrm{~N}$ has the minority spin electron dominant conduction current, which was recently predicted to be nearly half metallic. ${ }^{12,13}$ However, growth by reactive sputtering with low Co flux led to only $\mathrm{Fe}_{4} \mathrm{~N}$ peaks in the XRD. Figure 3 (a) shows the $\left(\mathrm{Co}_{\mathrm{x}} \mathrm{Fe}_{1-\mathrm{x}}\right)_{4} \mathrm{~N}$ thin film grown at low flux on TiN buffered Si substrate. Without capping layer on top of the thin film, an oxidation layer formed. In the HRSTEM image shown in Figure 3 (b), the surface oxidation layer has a similar structure as shown in Figure 2 (c). The EEL spectrum on the surface oxidation layer also has a pre peak in $\mathrm{O}$ $\mathrm{K}$ edge but no Co L edge shows up in Figure 3 (b), which means the surface oxidation is
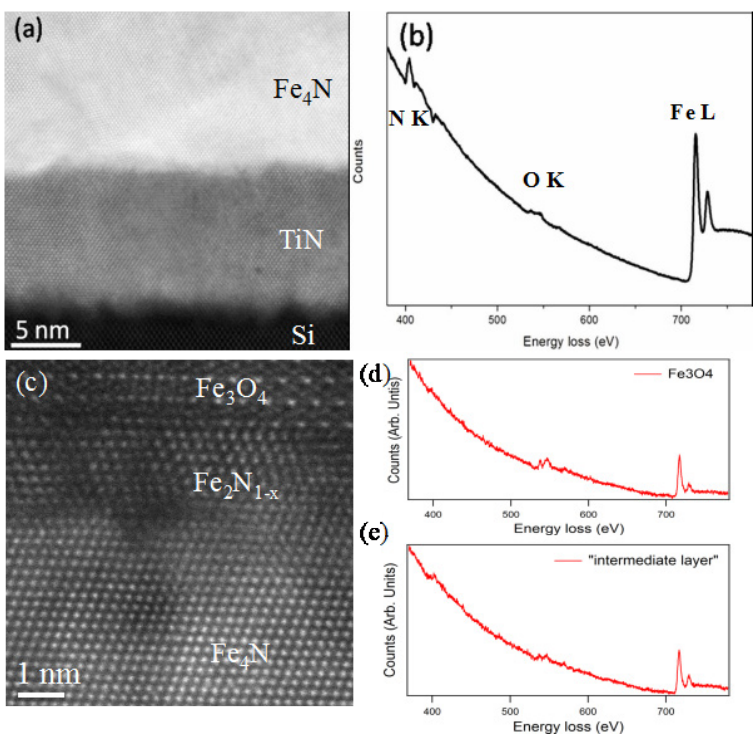

Figure 3 (a) HRSTEM image of all three layers from bottom to top is $\mathrm{Si}$, TiN and $\mathrm{Fe}_{4} \mathrm{~N}$, separately; (b) EELS spectrum on $\mathrm{Fe}_{4} \mathrm{~N}$ layer. (c) surface oxidation of $\mathrm{Fe}_{4} \mathrm{~N}$. Three layers in the (c) are identified as $\mathrm{Fe}_{3} \mathrm{O}_{4}, \mathrm{Fe}_{2} \mathrm{~N}_{1-\mathrm{x}}$ and $\mathrm{Fe}_{4} \mathrm{~N}$. (d) The spectrum taken on the $\mathrm{Fe}_{3} \mathrm{O}_{4}$ layer shows $\mathrm{O}$ $\mathrm{K}$ and $\mathrm{Fe} \mathrm{L}$ edge. (e) The spectrum taken on the intermediate layer shows $\mathrm{N} \mathrm{K}, \mathrm{O}$ K and Fe L edges.
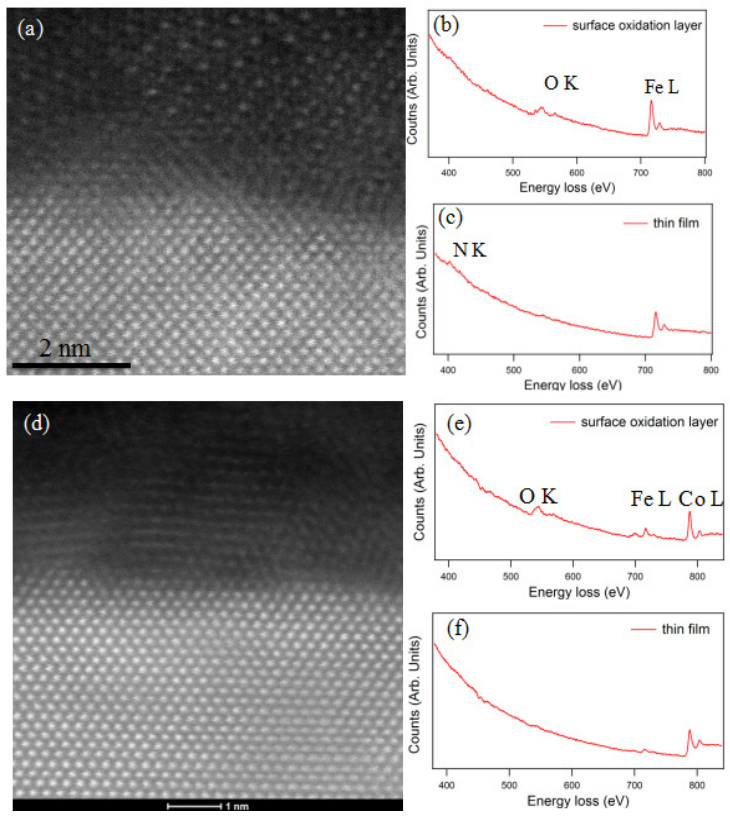

Figure 2 (a) A HRSTEM image of the interfaces between surface oxide and the $(\mathrm{CoFe})_{4} \mathrm{~N}$ thin film with low $\mathrm{Co}$ concentration. (b) and (c) are EEL spectra from surface oxide and the film, respectively. (d) A HRSTEM image of the interfaces between surface oxide and the $(\mathrm{CoFe})_{4} \mathrm{~N}$ thin film with high Co. (e) and (f) are EEL spectra from surface oxidation layer and thin film, respectively. 
completely Fe oxide. EEL spectrum in Figure 3 (c) shows that only Fe and $\mathrm{N}$ edges are presented, which might be due to the small Co depositing power.

Figure 3 (d) shows the thin films deposited with higher Co flux. The surface still has a thin layer of oxidized layer, but it is smoother than the low-flux film. EEL spectrum on the surface oxidation layer in Figure 3 (e) reveals that the oxidation layer contains Co and Fe with a Fe/Co ratio $0.52 \pm 0.12$. EEL spectrum on the thin film in Figure 3 (f) shows almost only Co L edges with $\mathrm{Fe} / \mathrm{Co}$ ratio $0.12 \pm 0.01$ and without $\mathrm{N} \mathrm{K}$ edge. From that result and XRD, we conclude that the film contains fcc $\mathrm{Co}(002)$ instead of $\mathrm{Co}_{4} \mathrm{~N}$ or $\left(\mathrm{Co}_{\mathrm{x}} \mathrm{Fe}_{1-\mathrm{x}}\right)_{4} \mathrm{~N}$.

In conclusion, we fabricated $\mathrm{Fe}_{4} \mathrm{~N}$ thin films by reactive sputtering, but we failed to fabricated $\mathrm{Co}_{4} \mathrm{~N}$ thin films due to its poor nitride formability by investigating through a series of $\left(\mathrm{Co}_{\mathrm{x}} \mathrm{Fe}_{1}\right.$ $\left.{ }_{x}\right)_{4} \mathrm{~N}$ thin films.

\section{$\mathrm{Fe}_{4} \mathrm{~N} / \mathrm{AlO}_{x}$ interface in a $\mathrm{Fe}_{4} \mathrm{~N} / \mathrm{AlO}_{x} / \mathrm{Fe}$ MTJ investigated by HRSTEM and STEM EELS}

We integrated $\mathrm{Fe}_{4} \mathrm{~N}$ electrodes in MTJs with $\mathrm{AlO}_{\mathrm{x}}$ as the tunnel barrier and $\mathrm{Fe}$ as one of the electrodes. Field cooling was done in air by keeping the as-prepared sample at $250{ }^{\circ} \mathrm{C}$ for 2 min and then cooling it to RT under a 1000 Oe magnetic field. Figure 4(a) and (b) show that the sign of the tunneling magnetoresistence (TMR) has changed before and after field cooling. Positive TMR (3.3\% under $0.02 \mathrm{~V}$ bias) is shown for the MTJ before field cooling, which is abnormal for a MTJ with a ferromagnetic electrode having negative spin polarization. However, after field cooling, we have a negative TMR instead (-5.7\% under $0.02 \mathrm{~V}$ bias).

HRSTEM and STEM EELS were applied to investigate the structures of the MTJs, especially the interface of $\mathrm{Fe}_{4} \mathrm{~N} / \mathrm{AlO}_{\mathrm{x}}$, before and after annealing. In Figure 4(c), we found a reaction layer formed at $\mathrm{Fe}_{4} \mathrm{~N} / \mathrm{AlO}_{\mathrm{x}}$ interface in the MTJ before field cooling (as deposited). The reaction layer has a many defects but also a different crystal structure from the $\mathrm{Fe}_{4} \mathrm{~N}$ thin film. After annealing, in Figure 4(d), the similar is present, but it has improved crystal quality. The crystal structure of the reaction layer is similar to that of $\mathrm{Fe}_{3} \mathrm{O}_{4}$ along a [110] zone axis.

Figure 4(e) and (f) show EEL spectra before and after annealing, respectively. Both spectra show the pre-peak feature on the $\mathrm{O} \mathrm{K}$ edge, which is consistent with the formation of some $\mathrm{FeO}_{\mathrm{x}}$ phase. ${ }^{14}$ Quantification of the reaction layer EELS as deposited shows that the $\mathrm{Fe} / \mathrm{O}$ ratio is $1.1 \pm 0.1$, close to FeO. EELS quantification on the reaction layer of junction after annealing shows $0.8 \pm 0.1$, which is close to $\mathrm{Fe}_{3} \mathrm{O}_{4}$. The formation of $\mathrm{Fe}_{3} \mathrm{O}_{4}$ is consistent with our results on the oxidation behavior of $\mathrm{Fe}_{4} \mathrm{~N}$.

In conclusion, we investigated the TMR, bias dependence, and microstructure of $\mathrm{Fe}_{4} \mathrm{~N} / \mathrm{AlO}_{\mathrm{x}}$ based MTJs. HR-STEM characterization finds a reaction layer at the $\mathrm{Fe}_{4} \mathrm{~N} / \mathrm{AlO}_{\mathrm{x}}$ interface which is primarily $\mathrm{Fe}_{3} \mathrm{O}_{4}$, with possible $\mathrm{FeO}$ or extra oxygen in the as-prepared state. After $250{ }^{\circ} \mathrm{C}$ field cooling, the EEL spectra show decreasing $\mathrm{Fe} / \mathrm{O}$ ratio from
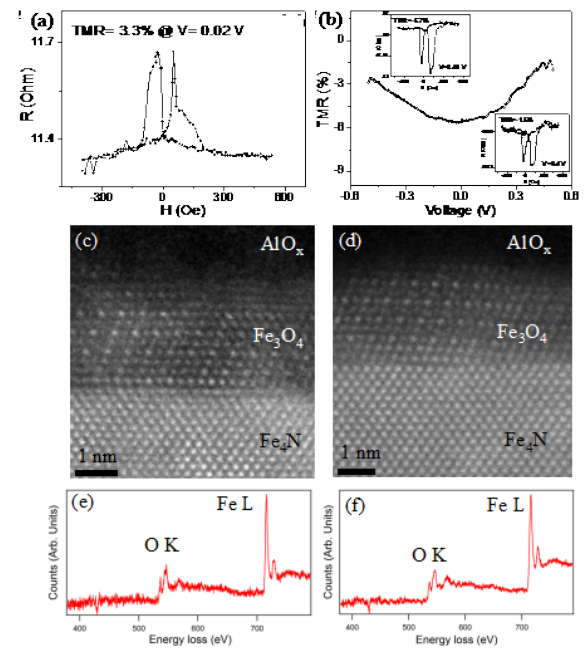

Figure 4 (a) and (b) show the TMR of the $\mathrm{Fe}_{4} \mathrm{~N} / \mathrm{AlOx} / \mathrm{Fe}$ MTJs before and after field cooling, respectively. (c) and (d) show the HRSTEM images of the interfaces for the MTJs before and after annealing, respectively. (e) and (f) show the EELS on the interface reaction layers before and after annealing, respectively. 

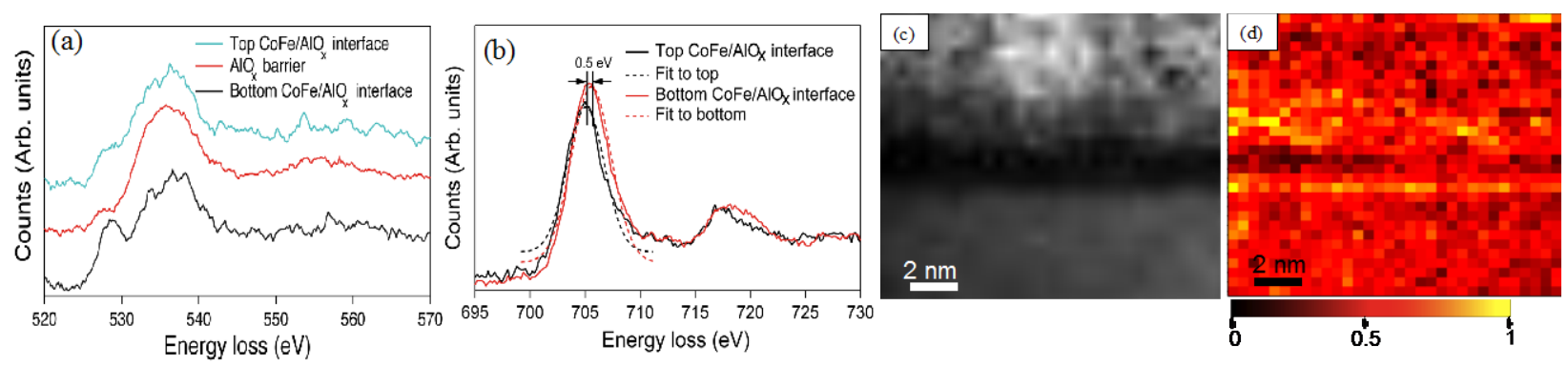

Figure 5 STEM EELS results on the inverse TMR after field cooling. (a) O K edge ELNES extracted from the barrier, upper and lower interfaces.(b) Fe L edge core level shift between upper and lower CoFe/AlOx interfaces (c) simultaneous HAADF image on the area where EEL SI was taken. (d) the intensity map of the pre peak of O K edge

$1.1 \pm 0.1$ to $0.8 \pm 0.1$, indicating the diffusion of the extra oxygen towards the $\mathrm{AlO}_{\mathrm{x}}$ barrier and improved $\mathrm{Fe}_{3} \mathrm{O}_{4}$ quality. The as-prepared junctions have normal TMR, which may result from the combination of an imperfect $\mathrm{Fe}_{3} \mathrm{O}_{4}$ layer containing $\mathrm{FeO}$ and extra oxygen at the reaction layer / insulator interface. We attribute the abnormal bias dependence to the formation of $\mathrm{FeO}_{\mathrm{x}}$ before and after field cooling.

\section{CoFe/AlO ${ }_{x}$ interfaces of the inverse TMR MTJ investigated by HRSTEM and STEM EELS}

We observed inverse TMR an MTJ with a symmetric structure Si (001) / Ag (buffer) / CoFe / $\mathrm{AlO}_{\mathrm{x}} / \mathrm{CoFe} / \mathrm{IrMn} / \mathrm{Ag}$ after it was annealed in air at $200 \sim 300{ }^{\circ} \mathrm{C}$ for $2 \mathrm{~min}$, then cooled to room temperature under a 1000 Oe magnetic field. STEM EELS spectrum imaging shows that a thin, discontinuous layer of $\mathrm{Fe}_{3} \mathrm{O}_{4}$ at the interface is the reason for the inverse TMR. ${ }^{15} \mathrm{Fe}$ L edge core level shifts extracted from STEM EEL spectrum images taken at the interfaces of the inverse TMR junctions show the formation of $\mathrm{Fe}_{3} \mathrm{O}_{4}$ at the interface of $\mathrm{CoFe} / \mathrm{AlO}_{\mathrm{x}}$.

In Figure 5 (a), the $\mathrm{O} \mathrm{K}$ edge ELNES extracted from the bottom interface of $\mathrm{CoFe} / \mathrm{AlO}_{\mathrm{x}}$ shows a pre-peak but none was observed at the lower $\mathrm{CoFe} / \mathrm{AlO}_{\mathrm{x}}$ interface and the $\mathrm{AlO}_{\mathrm{x}}$ barrier. The splitting between pre-peak and main peak agrees with our measurement on a $\mathrm{Fe}_{3} \mathrm{O}_{4}$ standard. The Fe L edge core level shift shown in Figure 5(b) shows a shift of $0.5 \mathrm{eV}$ to higher energy compared to $\mathrm{FeO}$, consistent with Hoefer et al. ${ }^{16}$ The simultaneously-acquired HAADF image is shown in Figure 5(c) and the intensity map of the pre-peak of $\mathrm{O} \mathrm{K}$ edge is shown in Figure 5(d), which also indicates the $\mathrm{Fe}_{3} \mathrm{O}_{4}$ formed only at the bottom $\mathrm{CoFe} / \mathrm{AlO}_{\mathrm{x}}$ interface. $\mathrm{Fe}_{3} \mathrm{O}_{4}$ is also found at the top interface. STEM EELS shows no sign of $\mathrm{Fe}_{3} \mathrm{O}_{4}$ at the interfaces of the MTJs with the TiN buffer and normal TMR, indicating that $\mathrm{Fe}_{3} \mathrm{O}_{4}$ is the reason for the inverse TMR.

We observed inverse TMR only in Ag-buffered samples after annealing and field cooling. We believe it is due to the high $\mathrm{O}$ solubility in $\mathrm{Ag}$. $\mathrm{O}$ has a relatively high solubility in $\mathrm{Ag}$ (about 2.24 c.c./g at $\left.300{ }^{\circ} \mathrm{C}\right),{ }^{17}$ so we speculate that the annealing released the $\mathrm{O}$ from the $\mathrm{Ag}$, it diffusesdto the tunnel barrier, then reacted with $\mathrm{Fe}$ in the electrodes to form $\mathrm{Fe}_{3} \mathrm{O}_{4}$. Although these MTJs are not optimized for the inverse TMR, they represent a particularly simple processing path to achieving inverse TMR, just by annealing. This may point to an easier way to control inverse TMR by manipulating the $\mathrm{O}$ in $\mathrm{Ag}$ using the annealing time and temperature. Other materials as buffer or capping layers might also be useful as oxygen reservoirs, like Ta, Ti, $\mathrm{Zr}$ and Hf, which also have high O solubility. ${ }^{18,19}$ 


\section{References}

${ }^{1}$ H. Xiang, F.-Y. Shi, C. Zhang, M.S. Rzchowski, P.M. Voyles, and Y.A. Chang, Scripta Materialia 65, 739-742 (2011).

${ }^{2}$ D. Margulies, F. Parker, F. Spada, R. Goldman, J. Li, R. Sinclair, and A. Berkowitz, Phys. Rev. B 53, 9175-9187 (1996).

${ }^{3}$ F. Shi, H. Xiang, M.S. Rzchowski, Y.A. Chang, and P.M. Voyles, MRS Proceedings 1430,(2012).

${ }^{4}$ H. Xiang, F. Shi, M. Rzchowski, P. Voyles, and Y. Chang, Applied Physics Letters 97, 092508-092503 (2010).

${ }^{5}$ J. Moussy, S. Gota, A. Bataille, M. Guittet, M. Gautier-Soyer, F. Delille, B. Dieny, F. Ott, T. Doan, P. Warin, P. Bayle-Guillemaud, C. Gatel, and E. Snoeck, Phys. Rev. B 70, 174448 (2004).

${ }^{6}$ D. Margulies, F. Parker, M. Rudee, F. Spada, J. Chapman, P. Aitchison, and A. Berkowitz, Phys. Rev. Lett. 79, 5162 (1997).

${ }^{7}$ S. Kokado, N. Fujima, K. Harigaya, H. Shimizu, and A. Sakuma, Phys. Rev. B 73, 172410 (2006).

${ }^{8}$ H. Xiang, F. Shi, M. Rzchowski, P. Voyles, and Y. Chang, Journal of Applied Physics 109, 07E126 (2011).

${ }^{9}$ M. Somers, B. Kooi, W. Sloof, and E. Mittemeijer, Surface and Interface Analysis 19, 633-637 (1992).

${ }^{10}$ Z. Liu, H. Hashimoto, E. Sukedai, M. Song, K. Mitsuishi, and K. Furuya, Phys. Rev. Lett. 90, 255504 (2003).

${ }^{11}$ Z. Liu, H. Hashimoto, M. Song, K. Mitsuishi, and K. Furuya, Acta Materialia 52, 1669-1674 (2004).

12 S. Matar, A. Houari, and M. Belkhir, Phys. Rev. B 75, (2007).

${ }^{13}$ Y. Imai, Y. Takahashi, and T. Kumagai, Journal of Magnetism and Magnetic Materials 322, 2665-2669 (2010).

${ }^{14}$ C. Colliex, T. Manoubi, and C. Ortiz, Phys. Rev. B 44, 11402 (1991).

${ }^{15}$ F. Shi, H. Xiang, J.J. Yang, M.S. Rzchowski, Y.A. Chang, and P.M. Voyles, Journal of Magnetism and Magnetic Materials 324, 1837-1844 (2012).

${ }^{16}$ H. Hoefer, G. Brey, B. Schulz-Dobrick, and R. Oberhaensli, Eur J Mineral 6, 407-418 (1994).

17 J. Simons, The Journal of Physical Chemistry 36, 652-657 (1932).

${ }^{18}$ R. Wasilewski, Journal of the American Chemical Society 75, 1001-1002 (1953).

${ }^{19}$ P. Kofstad, High-Temperature Oxidation of Metals (1966). 